\title{
Comunicação e Saúde Mental:
}

a Democratização dos Meios Comunicacionais

como Veículo de Reconstrução Identitária

\section{Communication and Mental Health: the democratization of the communications' media as an instrument of identity reconstruction}

Resumo: Este estudo aborda a emergência de novas formas de subjetivação no contexto da reforma psiquiátrica, tendo como referência os meios de comunicação, aqui particularmente considerando o veículo da TV Comunitária. Relata a experiência do núcleo de vídeo do Instituto Philippe Pinel do Rio de Janeiro, com uma proposta de televisão comunitária produzida pelos usuários da instituição. Aponta para a legitimidade da democratização desses meios como possibilidade de contrapartida ao processo de segregação social e ao assujeitamento psicótico fomentados pelo predomínio das práticas asilares que circunscreveram a doença mental historicamente. Reflete sobre as ações no âmbito local (embasadas nas relações de "pertencimento" e participação grupal) utilizando um meio global (linguagem televisiva) como importante via de reconstrução do lugar social do portador de transtorno mental.

Palavras-Chave: Saúde mental ,TV comunitária, reconstrução da identidade.

Abstract:This research approaches the emergence of new ways of subjetivity, according to the psychiatric reform, refering to the means of communication, emphasizing the Communitarian TV. It reports the experience between the video nucleus from Philippe Pinel Institute in Rio de Janeiro and a proposal from a communitarian channel, produced by the users of the institution. It points to the legitimacy of the democratization of these means against the social segregation and the psychotic subordination, supported by the asylum practices that embraced the mental diseases historically. It discusses the local actions (based on membership relationships and group participation) using a global way (television language) as an important way to rebuild the social place of the mental deficiency.

Key Words: Mental health, Communitarian TV, identity rebuilding.

Ilka de Araújo Soares

Psicóloga, pósgraduada em psicanálise. Mestre em comunicação e cultura (UFRJ).

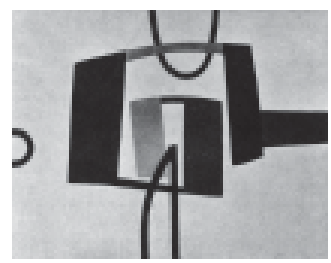

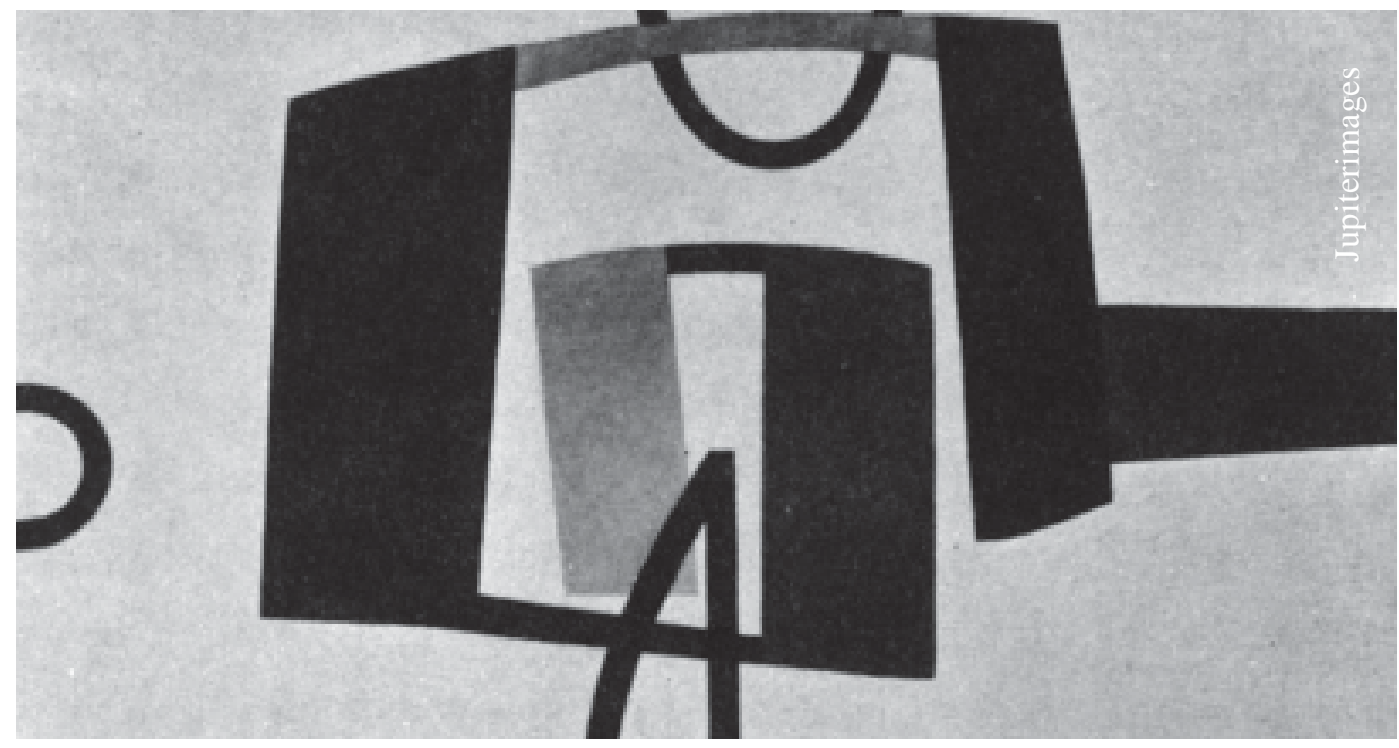

Não é de hoje que as abordagens à doença mental primam pelo acolhimento no interior de um espaço institucional, sendo outrora contextualizadas pelo predomínio do poder político sob a forma de Estado e da expansão de relações mercantis e técnicas de produção. A Psiquiatria, a justiça penal e a criminologia encarnaram, durante muito tempo, uma forma particular de poder em consonância com esse modelo, configurado enquanto produção de uma verdade sustentada por normas de conhecimento: o chamado poder-saber proferido por Foucault (1986). 
No que concerne à Psiquiatria, o lugar de inauguração de seu saber, o asilo, propagando a necessidade de sitiar para impedir a insurreição da loucura como foco da desordem econômica e política, se delineia pela máxima do disciplinamento. A intenção de comportar, em um espaço determinado, os ditos alienados, execrados do sistema social, se concretiza através de sua medicalização. Tendo como horizonte o poderio do médico sobre o paciente, a hospitalização, além de comportar modalidades interventoras punitivas de toda sorte, tem como meta central a produção da verdade da loucura "até então aprisionada e entravada”, constituindo-se "um lugar botânico para a contemplação das espécies, lugar ainda alquímico para a elaboração das substâncias patológicas” (Foucault, 1986, pp. 18-19).

A introdução das normas sociais no cotidiano do asilo, assim como a tentativa de "terapeutizá-lo" por intermédio dos planejamentos e recomendações de alguns médicos pioneiros, incluem, além dos procedimentos coercitivos e agressivos, técnicas variadas de intervenção como os programas arquitetônicos de contemplação de uma bela paisagem para cada cela, o uso de técnicas de dramatização para possibilitar o confronto do paciente com sua doença assim como métodos de encorajamento, recompensa e trabalho obrigatório.

Foucault retoma passagens dos textos do médico Esquirol, em que é proferida a necessidade de retorno dos alienados às "suas afeições", via pela qual compreende ser possível seu restabelecimento social. Cita que a possibilidade do processo de cura é promulgado por aquele médico mediante : "a volta às afeições morais dentro de seus justos limites, o desejo de rever seus amigos, seus filhos, as lágrimas da sensibilidade, a necessidade de abrir seu coração, de estar com sua família, de retomar seus hábitos”(1986, p. 121).

Essa concepção de exigência do resgate da interatividade social como forma de reabilitação, localizada nas origens da Psiquiatria, pode ser evocada, aqui, a título de correlação com o que atualmente ocorre nas práticas do campo da saúde mental, enfocando, em especial, o aspecto comunicacional aí imbuído.

Apesar de se manter como núcleo irredutível do pensamento científico, a relação de poder que o saber psiquiátrico engendra, concretizada pela verticalização das relações de poder entre médicopaciente nas instituições de tratamento, sofre intenso abalo no momento pós-moderno. É assim que as transformações velozes pelas quais o mundo tem passado nas últimas décadas, fomentando a suspensão dos alicerces das relações entre as esferas econômicas e políticas da sociedade, deixa entrever a crise nas disciplinas e coloca em questão os limites e certezas dos campos de conhecimento.

Se, no interior do asilo, todo o eixo de articulação das terapêuticas (com ênfase destacada nos aspectos menos punitivos) transcorre centrado na figura do médico e de seu saber, hoje, é sobre a flexibilização desses lugares que se erguem todas as perspectivas de reformulação das práticas, de redimensionamento do conceito de tratamento e do lugar do doente mental no contexto social, donde surgem as novas configurações e modelos que intencionam uma interferência no processo histórico que condiciona tal panorama.

A instituição asilar ganha contornos de denúncia de sua insuficiência terapêutica, tendo sua manutenção e subsistência justificadas pelo hiato entre as transformações tecnológicas e intervenções socioculturais. O recurso asilar persiste face à inércia político-econômica no gerenciamento e na concretização dos modelos substitutivos, à precariedade da assistência em saúde mental e ao suporte que concede a uma enorme população desprovida de recursos habitacionais e sociais. Estremecendo-se as instituições tradicionais, afrouxando-se o elo de aliança do doente sob os auspícios do olhar do médico, o que sobrevem? Uma vastidão de propostas alternativas de tratamento, a urgência de novas sustentações políticas que as dimensionem, questionamentos sobre a doença mental contextualizada socialmente, daí advindas as discussões sobre os conceitos de reabilitação e cidadania.

O potencial da linguagem, enquanto importante preceito simbólico veiculado pela abordagem teórica do campo comunicacional, apresenta-se, nas práticas da saúde mental, como via essencial de um novo campo de deliberação para refletir os impasses advindos da suspensão das relações verticalizadas, solidamente demarcadas nas instituições asilares, bem como diretriz para repensar as vicissitudes do posicionamento social dos sujeitos psicóticos, marcados por sua notória incomunicabilidade social.

Se respaldadas pelas transformações contemporâneas e pela produção de novas formas de democratização social, essas ações podem delinear-se por dispositivos de territorialização, sustentados nas relações de pertencimento, de inerência social, fomentados por intermédio das práticas grupais e subsidiados pela convocação continuada de participação no processo social. Essa convocação é dirigida, especialmente, aqui, aos sujeitos concebidos como "alienados, antisociais, narcísicos ou delirantes”, donde faz-se necessário particularizar algumas considerações.
" $a$ volta às afeições morais dentro de seus justos limites, o desejo de rever seus amigos, seus filhos, as lágrimas da sensibilidade, a necessidade de abrir seu coração, de estar com sua família, de retomar seus hábitos”

Foucault 
Mucchielli (1971, pp. 86-91) aponta que as perturbações mentais "podem ser entendidas como doenças da comunicação" . Esse autor descreve quadros psicóticos em que prevalecem desde uma comunicação ilusória até formas em que essa comunicação é recusada de maneira passiva (catatonia), ou apresentada de modo ativoagressivo (forma paranóide), ou concebida como esvaziada de sentido (na melancolia), ou, ainda, manifestada com uma intensidade comunicadora cuja fugacidade e fluidez excessiva (mania) revelam o aspecto incoercível das manifestações e a superficialidade de sua expressão.

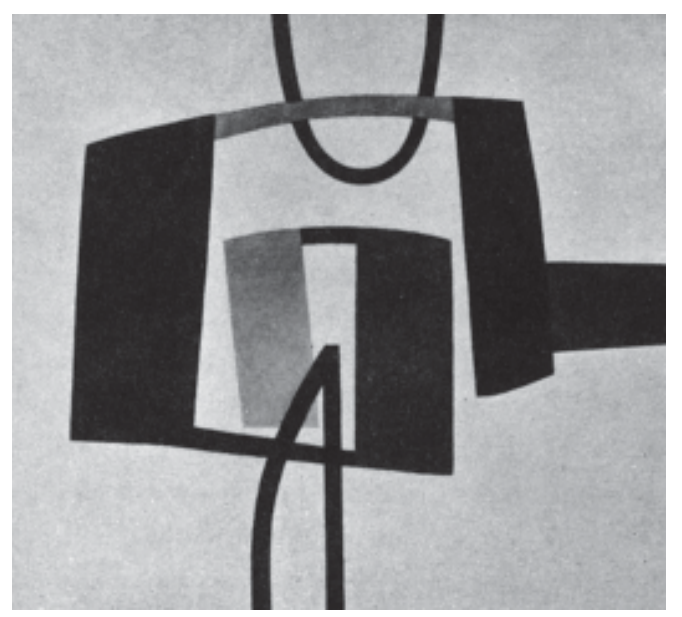

"promovem a formação de grandes concentrações de poder econômico $e$ simbólico que são privadamente controlados $e$ desigualmente distribuídos, e que dispõem de recursos maciços para garantir os objetivos corporativos da arena global"

Thompson
Seria, então, um paradoxo proferir a convocação processo social mediante os mecanismos comunicacionais? Balizados por argumentos teóricos que proferem que a essência dos problemas mentais concerne a um distúrbio da relação inter-humana, alguns autores apostam exatamente na inclusão do dispositivo grupal nas esferas institucionais ou comunitárias enquanto modo de restabelecimento da comunicação social, paradigma enfático no contexto da reforma psiquiátrica.

Nesse contexto, os grupos são concebidos como espaços genuínos de produção de importantes engrenagens de construção de uma cidadania particular, através da propriedade (gerada pela emergência, no seu interior, de novos mecanismos de comunicação) de gestão reinvidicatória, intermediada pelo viés comunitário.

É assim que as terapêuticas institucionais alternativas ao asilo, pautadas pelo dispositivo comunicacional, pela interação grupal e, principalmente, pela possibilidade de construção de um formato institucional específico, que "não sabe” previamente, propiciando, assim, a construção de um saber do sujeito (Miller, 1983), continuada desses sujeitos à participação no poderiam ganhar uma conotação totalmente diversa daquela descrita inicialmente com relação aos elementos predominantes no modelo de hospitalização psiquiátrica.

Enfocando especificamente as relações no campo institucional, Guattari (1992, p.188) afirma que o mundo altero com o qual a psicose entra em diálogo "não é unicamente de ordem imaginária, delirante e fantasmática...encarna-se igualmente no meio social e material do cotidiano". Isso equivale a dizer que a fomentação de mudanças "no campo intrasubjetivo e no contexto pragmático”(pp. 188), criadas com base no viés comunitário, podem criar condições favoráveis para transformações significativas na particularidade comunicacional da psicose.

\section{A Tv Comunitária e a Reinvenção da Imagem da Loucura}

A tendência crescente de interconexão entre diferentes partes do mundo, através da extensiva proliferação dos canais de comunicação e da difusão de informação, tem trazido complexidade às formas de interação social. O caráter desigual da comunicação globalizada se evidencia mediante o desenvolvimento de conglomerados de comunicação, que, conforme aponta Thompson :

"promovem a formação de grandes concentrações de poder econômico e simbólico que são privadamente controlados e desigualmente distribuídos, e que dispõem de recursos maciços para garantir os objetivos corporativos da arena global” (1998, p.144).

O material simbólico globalizado, além de ser marcado por disparidades no seu acesso, demonstra, também, níveis de captação distintos bem como diversos modos de utilização dos conteúdos globalizados, que incluem incorporação, entendimento e interpretação diferenciados, relativos à circulação das formas simbólicas.

Fomentadas por uma vastidão de imagens, temas e representações, as produções da indústria da mídia, difundidas globalmente, além de repercutir na dependência cultural de grupos sociais diversos, ao expediente cultural dominante, induzem à consolidação de novas demandas simbólicas. Tal processo se caracteriza pela complexidade, variedade e especificidade dos modos de interpretação das mensagens, cujo conteúdo daí resultante passa a ser incorporado na vida cotidiana desses grupos.

Em uma visão interacionista e positiva sobre o processo, Thompson observa que a veiculação de 
imagens e mensagens oponentes com os valores da Tradição, no processo de apropriação localizada dos produtos globalizados da mídia, permite o acesso a novos tipos de materiais simbólicos, o que implica uma ressonância sobre a autoformação identitária de indivíduos participantes de determinados grupos sociais. $\mathrm{O}$ cultivo de crenças e valores tradicionais ganha uma conotação remodelada pelo atravessamento das formas simbólicas mediadas.

Sobre esse aspecto, é possível refletir que a apresentação, na mídia, de aspectos historicamente delineados, cristalizados tradicionalmente pelo invólucro de cunho estigmatizante e excludente, quando revestidos em novas retóricas de produção simbólica, podem ocasionar seu redimensionamento na concepção social dos discursos. Assuntos como a reforma psiquiátrica, novas formas de assistência aos pacientes psiquiátricos, divulgação de projetos de lei que se direcionam à temática da doença mental, etc., por exemplo, ao serem divulgados pelos meios de comunicação, ressoam enquanto dispositivos de convocação de reconceitualização das convicções intensamente enraizadas sobre o problema .

É inegável, entretanto, que a apropriação dessas questões pela grande mídia tende a esvaziar qualquer indício de produção de sentido genuinamente transformador na medida em que sua exposição é veiculada de forma a evitar embates com conceitos socioculturais predominantes. Às vezes, sob a fachada de discursos libertários, fomentam incisivos processos de reprodução cultural e ideológica engendrados sobre os alicerces do domínio visual e dos processos mecânicos de reprodução, que caminham no sentido da dissimulação e da absorção das diferenças e no esmorecimento das contradições sociais.

A prevalência dos processos de reprodução das informações e imagens, mediadas principalmente pela televisão, ocupa importante lugar diante das novas formas de urbanização. O esgotamento dos modelos tradicionais de representação face à incrementação dos modos de produção capitalista situa os mass-media enquanto importantes operadores e indutores de "hábitos, crenças e modos de percepção...”, promovendo a integração dos indivíduos na estrutura sociocultural como “sujeitos-consumidores” e constituindo-se em um novo modo de estruturação das relações humanas (Sodré, 1984, pp. 41,131). Os mass-media, articulados aos modos de organização do espaço social e à produção dos discursos sociais, dissolvem os laços comunitários, “serializando os consumidores e homogeneizando a cultura” (p. 46).
O vazio institucional a que ora se assiste, o desvanecimento dos valores tradicionais, a falência da referência concreta, encontra na telerealidade uma garantia de visibilidade do real ressurrecto através dos dispositivos de reinjeção de sentido, marcados pelo predomínio da produção de imagens e representações que denotam a circunscrição do relacionamento social centrado "no contato à distância e no olhar' (p. 143). Simulando o mundo, a televisão denuncia a morte dos modelos tradicionais e partilhados de representação, que, por sua vez, somente são capazes de assumir essa dimensão frente aos modos de organização da sociedade pós-moderna, ou seja, a televisão, da forma que se difunde, não constitui um dispositivo técnico de transmissão de imagens funcionando isolada e aleatoriamente, mas, antes, um modelo articulado e orientado em consonância com o inovado modo de organização do espaço social.

Conforme aponta Barbero (1998, pp.249-250), o refinamento dos dispositivos ideológicos da televisão, revestidos de maior complexidade de organização industrial e investimento econômico, permite que ela produza uma unificação da demanda que é "uma maneira de conseguir a expansão do mercado hegemônico sem que os subalternos se ressintam dessa agressão". Desenvolvendo ao máximo a absorção e o controle das diferenças, balizados por diretrizes da ordem do consumo, a televisão cuida de apresentar os conteúdos com manobras decodificadoras específicas, impedindo que o diverso questione o telespectador, "chocando minimamente os preconceitos socioculturais das maiorias”.

Entretanto, as tecnologias aí engendradas tornam visível "um resto não simulável, não digerível, que, a partir da alteridade cultural, resiste à homogeneização generalizada” (p. 254). O atravessamento das mensagens por diversas trajetórias de sentido subentende que não apenas há reprodução mas também uma produção sobre as mesmas, tornando possível pensar na existência de lugares de onde provêm construções que redimensionam a "expressividade cultural da televisão” (p. 292) . É no espaço de produção de artimanhas ambíguas e ideológicas que é possível entrever as contradições inerentes à TV, que permitem constatar a não unificação do universo simbólico, supostamente almejada na intervenção desse dispositivo enquanto recurso hegemônico. É por meio dessas brechas que emergem novas demandas (subvertendo a reprodução ideológica e cultural) que tendem a recuperar, com o uso desse mesmo dispositivo, nesse mesmo campo de consumo, inovados e diferenciados discursos sobre a realidade sociohistórica . 
"É da constatação de que as diferenças e conflitos não se reduzem a uma identidade homogênea, que se pronuncia a compreensão do desenvolvimento das mídias alternativas, dos meios de comunicação de uso comunitário. Estes visam o reconhecimento de identidades sociais múltiplas, cuja ótica versa exatamente pelo seu uso, como forma de legitimação de comportamentos e existências que se baseiam em patamares diferenciados daqueles predominantemente evocados no uso corrente dos meios de comunicação" .

Face ao predomínio de um gigantesco processo de simulação nos meios televisivos hegemônicos que tende a extrair as possibilidades de produção de sentido, e diante dos quais apenas é possível posicionar-se pelo fascínio e pela imersão na imaginação, os veículos comunicacionais comunitários investem em uma proposta alternativa. Embora não abrindo mão do desenvolvimento tecnológico (estando, portanto, condicionados aos mecanismos prevalecentes nesse campo), utilizando um meio compatível com o processo global, essas iniciativas distanciam-se, entretanto, do que se supõe ser o poder isolado e esvaziado de sentido engendrado naquele.

Isso ocorre por essas iniciativas se referenciarem na união de pessoas com objetivos partilhados, cujas práticas são balizadas na inscrição de um determinado pertencimento territorial, na importância do poder decisório entre os membros e na tentativa de retratação de seu real-histórico através do meio comunicacional escolhido. Referendadas pela especificidade de grupos determinados, as iniciativas dos meios de comunicação comunitária se consolidam pela possibilidade de promover a conscientização sobre suas causas, reivindicação de cidadania e mudança efetiva de sua realidade.

No caso do produto que se pretende, aqui, enfocar, a "TV Pinel", a tentativa de reconstruir as representações sociais da loucura a situa como um instrumento de visibilidade interessante no contexto da reforma psiquiátrica do Brasil. A empreitada de partir da mídia rumo ao reposicionamento de concepções cristalizadas no imaginário social sobre a loucura se concretiza com a utilização de práticas de democratização comunicacional e do aproveitamento de discursos criativos e originais sobre a questão da loucura, produzidos pelos próprios usuários participantes da TV.

A iniciativa da TV surgiu da experiência do núcleo de vídeo do Instituto Philippe Pinel (Rio de JaneiroRJ), que consistia em uma oficina de aproximação com fins de disponibilizar a linguagem audio-visual aos usuários da instituição. Essa experiência foi ampliada para a proposta da TV Comunitária que, na sua formação inicial, teve entrada e escoamento da produção no Canal Saúde (TVE, Fiocruz e Embratel). A TV teve várias premiações em festivais de vídeos nacionais e internacionais e, atualmente, tem um fluxo grande em espaços televisivos diversos, dentre eles o Canal 14, Programa da Faixa, etc.. É composta por uma equipe de 15 pessoas, dentre estas, técnicos de vídeo, jornalismo, usuários em tratamento na rede pública de saúde mental, câmeras, etc., que tiveram o financiamento inicial de seu trabalho gestado pelo Ministério da Saúde e atualmente têm seus contratos efetuados via município. Conta com a assessoria da ONG Imagem na Ação), que articula o projeto de autogestão interna da TV. Os usuários, alguns com funções fixas e específicas, recebem pagamento pelo desempenho de seus trabalhos profissionais.

A proposta comunitária vincula-se diretamente à forma pela qual o grupo concebe a questão da identidade na loucura. Os dados expostos a seguir foram extraídos de entrevistas com usuários e técnicos da TV.

Aspectos como divisão de tarefas, atribuições de funções de acordo com as habilidades( se usuário ou técnico, as funções são distribuídas de acordo com as habilidades e possibilidades de cada um), participação do usuário em todas as etapas do processo de realização dos produtos e, principalmente, nas reuniões de cunho deliberativo, escolha e criação das temáticas a serem apresentadas pelos usuários (diante das quais cabe ao técnico servir de provedor de acesso dessas pessoas à linguagem), horizontalização da comunicação entre os membros, etc., são pontos que marcam o funcionamento desse trabalho enquanto iniciativa comunitária.

É sabido que as propostas atuais de abordagem à doença mental tendem à ruptura com a centralidade do modelo "biomédico". Isso tem apontado para, além do aspecto multiprofissional nos trabalhos institucionais, a tendência de inclusão de novos saberes, novos olhares acerca da questão. A inserção da iniciativa comunitária e da participação grupal são vieses importantes na prática da reabilitação, que se consolidam a partir e para além de campos disciplinares tradicionais. O fato de não haver, na equipe, técnicos "psi" ligados, no cotidiano, ao exercício prático do trabalho da TV (o trabalho conta com coordenação e supervisão técnica da psicóloga Claudia Corbisier) induz os participantes a questionarem, no dia a dia, "sobre a melhor forma de lidar com os usuários”. Um técnico expõe o que pensa sobre isso: “Algumas pessoas dizem que esta é a chave do sucesso... Alguns técnicos da equipe vêm de uma experiência de trabalho em 
comunidade... Para a gente, todo mundo é japonês... Vemos que o aprendizado aqui é lidar com as diferenças, que na verdade não é só a diferença de quem tem problema mental ... Tem pessoas que não têm problema mental e que têm dificuldades com o desempenho de funções...Quando os visitantes entram aqui, uma dificuldade é saber quem são os pacientes... Acho que este espaço é terapêutico, porque é um espaço de acolhimento...Tem um clima de afetividade... Aprendemos também a lidar com a questão da loucura de um prisma diferente do assistencialismo ou daquela coisa do asilo em que as pessoas ficam em uma situação de proteção e de anonimato e quando saem de lá, costumam ir para um movimento inverso, de achar que podem tudo, que a "reforma" lhes permite tudo, não se responsabilizam e não aceitam os limites...”

Algumas falas de usuários sobre suas vivências de adoecimento psíquico revelam a maneira singular de retratá-la, positivando-as expressivamente nos conteúdos e temas criativos de seus programas. “Não jogue fora a sua loucura...Ela é real”, expressa um usuário. Na programação exibida, é incluído o Telejornal Pinel, com notícias sobre as atividades internas do Instituto, as alternativas frente à internação psiquiátrica, dicas de atividades culturais na cidade, etc.. Esse programa expõe o compromisso com as instituições de tratamento, a tentativa de transmissão sobre as novas propostas de assistência, as possibilidades na inserção social do usuário e a responsabilidade deste na informação e argumentação acerca do problema mental .

Muitos programas, enquetes, clipes e reportagens ganham um tom bem humorado e satírico sobre a loucura. Produzidos pelos próprios usuários, esses programas buscam mostrar como a circunstância da doença pode ser vista ou representada por eles, de uma forma diferente da que, em geral, é concebida. Introduzindo novas versões sobre a forma como gostariam de ser vistos, os usuários utilizam uma linguagem criativa e jocosa que visa ressoar na luta contra o lugar estereotipado do louco enquanto doente e marginalizado social.

Descreve um técnico que uma coisa com a qual efetivamente se rompe, nesta proposta interna de intervenção com a loucura, é que as pessoas não são concebidas, aí, como portadoras de uma identidade fixa e única, o que aponta para a elucidação do fenômeno da pluralização identitária, característico da contemporaneidade, que, supostamente, aqui, estaria abrindo "brechas" para que esses sujeitos excluídos e identificados cristalizadamente no estereótipo de marginalizados possam apresentar-se de formas mais flexíveis. Menciona o técnico: “aqui não pensamos que o louco tem uma identidade fixa. Ele pode ser louco, sim, mas não é só isto, ele é pai, filho, profissional, casado, solitário, etc. ... Não colocamos, por exemplo, na apresentação e discriminação das funções sobre os programas desenvolvidos, a relação entre 'Fulano e usuário', mas sim 'fulano vinheta', ‘fulano - iluminação', etc..”

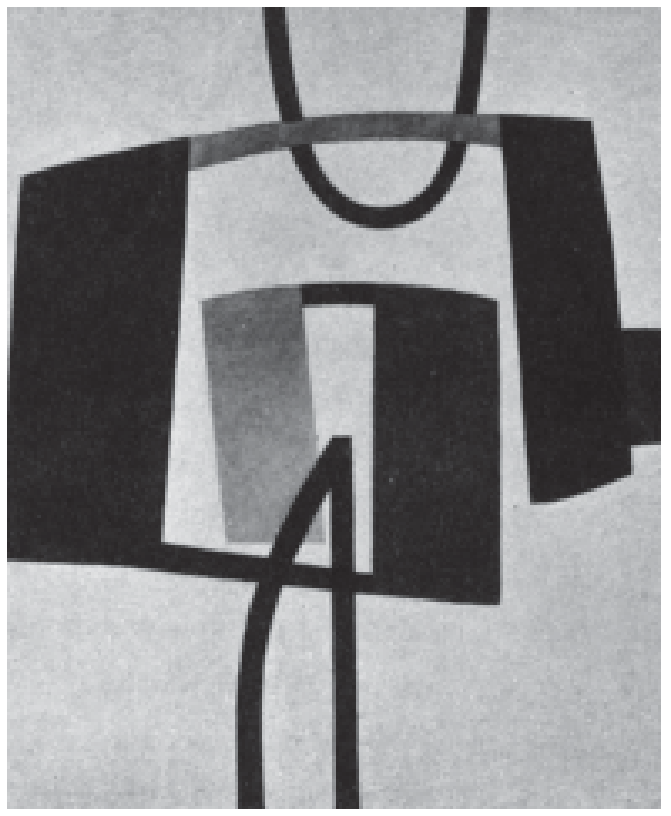

“Não jogue fora a sua loucura...Ela é real", expressa um usuário. $\mathrm{Na}$ programação exibida, é incluído o Telejornal Pinel, com notícias sobre as atividades internas do Instituto, as alternativas frente à internação psiquiátrica, dicas de atividades culturais na cidade, etc..
Na TV Pinel, enquanto mídia alternativa, a comunicação comunitária reveste os aspectos estruturantes desse tipo de meio de algumas peculiaridades. A estrutura comunicacional, que diz respeito à consolidação da comunicação social e da interatividade mediante a organização de trocas reais na prática grupal, se destaca aqui, enquanto forma de intervir no que se supõe ser o problema inter-relacional, na dificuldade de autopercepção, de representação de papéis em situações sociais, no desfavorecimento da auto-imagem, etc. , questões que estão na base das articulações das propostas de reabilitação psicossocial no contexto da reforma psiquiátrica. A rede de comunicação consiste no meio material de transmissão de mensagens, caracterizado pela escolha das vias de comunicação adequadas para essa transmissão (é o elemento a priori das comunicações no grupo) e que veicula uma estrutura comunicacional específica (Mucchielli, 1971), cuja finalidade, no caso, é descrita como a reconstrução, no imaginário social, do lugar dos membros envolvidos no processo.

Se, em todos os grupos que se inclinam ao desenvolvimento dos meios de comunicação, esses dois vértices se apresentam, as peculiaridades de sua apresentação no produto comunicacional TV 
Pinel deve ser ressaltada por envolver pessoas para quem a questão da especificidade simbólica é algo que as particulariza frente à realidade social.

É possível refletir sobre a particularidade simbólica na psicose, marcada pela ejeção da partilha de códigos sociais. Situado enquanto ponto nodal da constituição do Eu por intermédio da imagem do Outro, o Estádio do Espelho acena a possibilidade para o sujeito de, precipitando-se da insuficiência para a antecipação (Lacan, 1966, p. 100), constituirse pela imagem espelhada do Outro, rumando, a partir daí, em direção à integração em um circuito dialético com este. A não vivência da dimensão de intervalo na psicose, a não inscrição da Metáfora Paterna com prejuízo no endereçamento do sujeito para além da relação dual compromete sua localização na ordem simbólica.

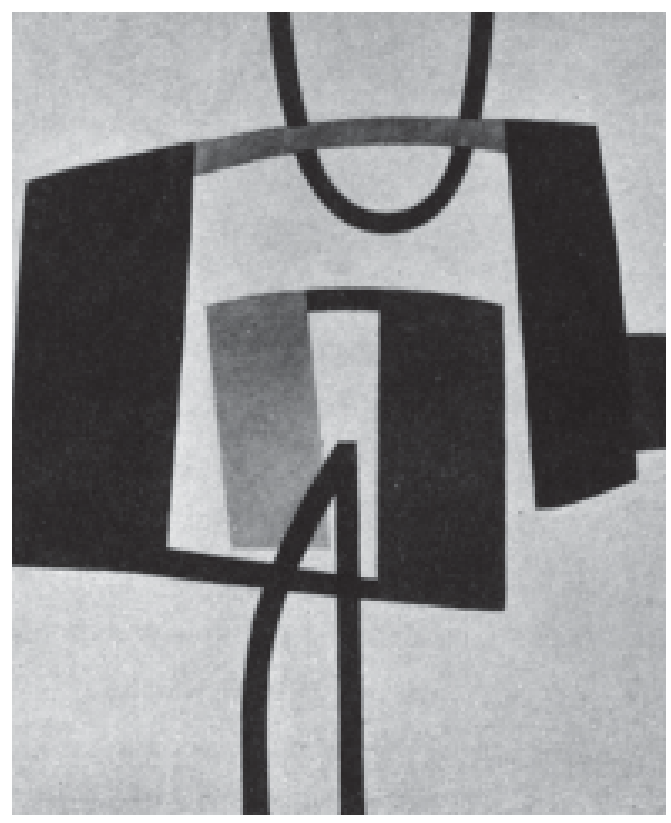

Estudos de casos que inferem a ocorrência de um processo de estabilização psíquica através do uso do recurso da reprodução televisiva insinuam que tal recurso pode acenar para alguns sujeitos como "empréstimo" de elementos dos quais estruturalmente acham-se desprovidos. O recurso televisivo (ver-se projetado, aperfeiçoar a forma de exposição, elaborar textos, entrevistar, filmar, etc.) pode constituir-se em objeto capaz de dar consistência à imagem corporal, conferindo contornos ao corpo imaginado em fragmentos, através do centramento e da circunscrição da imagem televisiva (donde se pode ler o artifício televisivo de invólucro do real). Isso aponta para um movimento possível para além do reforço das se de uma maneira singular) estaria acenando a "tomada de enunciação" pelo sujeito, “descompletando", assim, o saber absoluto do Outro a seu respeito.

Ver-se tecnologicamente reproduzido pode ganhar nuanças especialmente vitais aqui. Pode-se tomar emprestado a citação de Mumford que, face à desintegração psíquica, é plausível que o indivíduo "se volte na direção da imagem solidária para ver, verdadeiramente, quem ali está e o que é preciso atingir” (apud Sodré, 1984, p. 132). Longe da citada plausibilidade, na psicose, esse recurso (de dirigirse e utilizar a imagem) insinua ganhar dimensões essenciais, aqui, tendo em vista a possibilidade de remediar minimamente o percalço simbólico predominante, através do trabalho rumo a uma ancoragem possível e da aquisição de uma nomeação e significação próprias, criando um laço social novo, até então inacessível para alguns sujeitos.

Correlativamente aos estudos de casos, é possível vislumbrar que a dinâmica de formação do processo grupal na prática comunitária, com o uso da TV, constitui-se em um dispositivo de reabilitação psicossocial possível no contexto da reforma psiquiátrica através da promoção de intercâmbio com a realidade e do redimensionamento da concepção social acerca da loucura.

A televisão, independente do uso a que se presta (se hegemônico ou comunitário) enquanto equipamento fundamental de simulação do mundo, pauta-se na objetivação do imaginário, reproduzindo imagens que alteram a lógica dialetizante presente nas relações sociais face a face . Estimulando retoricamente o olhar, a TV fascina-o, ocultando a assimilação psicológica dos indivíduos, os telespectadores, consciências narcisicamente dirigidas pelo movimento reflexivo das representações televisivas. O apelo pela assimilação e identificação com as imagens funcionam no sentido de promoção e ascensão dos simulacros a um princípio de realidade (Sodré, 1984, pp. 131- 67).

Essa forma de operacionalização da TV localiza-a enquanto dispositivo, por excelência, de sedução pelo registro imaginário. Mesmo estando a serviço de usos diversos, cuja finalidade é a introdução de sentido (e não seu desfalecimento), como no caso das comunidades que intencionam sua representação social, política, etc., mesmo não se pautando na órbita restrita e direta da exibição, da espetacularização, mesmo enquanto mídia alternativa, a TV se consolida face ao predomínio do aspecto ilusionista e imaginário. No caso do produto aqui analisado, a TV veicula um apelo à causa de reconstrução da imagem da loucura. 
A entrada em circulação de causas como essas põe em questionamento os signos implícitos na comunicação. Marafioti (1993) aponta que o processo de significação de produtos colocados em circulação agrega um valor a mais que o próprio texto apresentado.

A ampliação do conceito de mensagem a situa na obediência ao requerimento de uma lingüística discursiva que excede o nível da frase para alcançar unidades "transfrásicas" mais gerais, com suas regras de produção particulares (Marafioti, p. 139). A concepção de interação comunicativa entre um veículo de comunicação comunitária colocado em circulação não diz respeito exatamente a que, no âmbito da transmissão das mensagens, haja uma ruptura incisiva com a homogeneidade reinante nos dispositivos comunicacionais hegemônicos, mas, antes, que possa ocorrer a convocação de óticas sociais diversas que são postas em funcionamento para a decodificação dos textos emitidos e que acionam a retroalimentação do imaginário inerente às relações de troca entre os sujeitos envolvidos no processo comunicacional.

Daí se prefigura que, em uma perspectiva pragmática da linguagem difundida por um veículo de comunicação de propagação ampla como a TV, movida por causas comunitárias, o ato de falar não pode restringir-se, de modo algum, ao âmbito da informação, constituindo-se, antes, no sentido da argumentação, donde pode-se ler que a produção de conteúdos que se pretendem reformuladores não se assentam no prisma estrito da transmissão de coisas novas, mas, antes, na transmissão de "coisas que trazem conseqüências" (p.259).

$\mathrm{Na}$ TV Pinel, as tentativas de retratação e reinvenção da imagem da loucura insinuam incidir enfaticamente sobre o imaginário social segregacionista. Atuando no sentido de convocar um olhar diferenciado sobre a loucura, introduz signos lingüísticos distintos daqueles comumente difundidos a seu respeito. O tom humorístico dos programas e mensagens e a difusão da idéia de que loucura "não é sofrimento o tempo todo..." (usuário da TV) evoca, através da reprodução tecnológica de si mesmo, o auto-reconhecimento, pelo Outro, de um outro lugar. Esse reconhecimento delineia-se na sedução suscitada pelos recursos televisivos e na provocação de uma manobra de reviravolta das adjetivações e representações clássicas do real histórico, que, enquanto restritas nesse âmbito, se perfilam na estigmatização e marginalização social do louco.

A reconstrução de sentido produzida pelo meio televisivo, especialmente aqui, diz respeito à reconfiguração de uma realidade altera que circunscreve a existência dos sujeitos envolvidos, apreendida na prática comunitária enquanto algo que urge seja redimensionado no que tange às atribuições sociais a seu respeito. A ênfase na reconstrução da imagem da loucura com a utilização de signos de satirização e humor mostra, por exemplo, uma face do processo comunicacional em que o elemento subentendido, a exclusão social, é antecipado, sem o dizer e, ao mesmo tempo, dizendo-o. Mediante essa forma de utilização de signos, em que um signo remete a outros, a exclusão social é inserida, enquanto algo passível de ressignificação, podendo produzir uma cumplicidade fundamental que liga os participantes do ato de comunicação.

Em se tratando de enfocar a utilização de um meio de comunicação de expressão prioritariamente Global, que passa a ser utilizado na esfera do Local, Canclini (1999) pronuncia a complexidade desse processo. Delineia que o que parece estar em questão são as oportunidades aí geradas, de convivência com a heterogeneidade, a diferença e a desigualdade. Não reduzido à esfera da oposição entre Global e Local, o processo revela a necessidade de enfoque sobre o imaginário produzido na constituição de novas mediações nos dois pólos.

O autor destaca que o surgimento de espaços inovados de intermediação cultural e sociopolítica, enquanto instituições mais flexíveis, podem constituir-se em vias de proliferação de redes dedicadas à "negociação da diversidade" (p. 31). A TV Pinel, nesse sentido, trabalha rumo à reconfiguração da imagem da loucura em uma escala mais ampla, contribuindo para a possibilidade de reconceptualização cultural desta. Levantando questões transcendentes à esfera do Local, essas ações tendem a projetar suas perspectivas em uma escala que ultrapassa o caráter reativo de um movimento defensivo que, aqui no caso, se pauta na causa da loucura. A elaboração desse projeto tem, no horizonte, a utilização de meios globais ( linguagem televisiva), assim como tem recrutado a participação simultânea dos membros em todo o processo, trabalhando no sentido de uma organização interna embasada nas relações de participação comunitária (local).

A democratização da comunicação, a apropriação dos meios massivos para a efetuação de comunicação das minorias, a invenção de novos sentidos e dispositivos de expressão singulares tem sido apontada como forma alternativa de operar frente à massificação estética e ideológica de padronização e homogeneização das sociedades, solidificada pela grande mídia (Peruzzo, 1998,

\section{A ênfase na} reconstrução da imagem da loucura com a utilização de signos de satirização e humor mostra, por exemplo, uma face do processo comunicacional em que o elemento subentendido, a exclusão social, é antecipado, sem o dizer e, ao mesmo tempo, dizendo-o. Mediante essa forma de utilização de signos, em que um signo remete a outros, a exclusão social é inserida, enquanto algo passível de ressignificação, podendo produzir uma cumplicidade fundamental que liga os participantes do ato de comunicação. 
p.19). Entretanto, é preciso ressaltar, sempre, a necessária postura de não imersão na concepção de um triunfalismo pela simples introdução de um meio popular como algo essencialmente libertador. Sabendo que a reprodução de valores ideológicos é mais fácil do que sua transformação é que se evoca a necessidade contínua de avaliação dos elementos presentes no processo de comunicação e da importância de sua organização em torno dos interesses coletivos dos sujeitos inseridos que tenham um vínculo orgânico com a realidade local à qual se presta.

Técnicos da TV Pinel referem-se à crítica externa dirigida à sua forma de apresentação dos programas, da ausência de enfoque explícito à dor e à exclusão social. $\mathrm{O}$ fato de os usuários se dizerem da forma que até então lhes tem sido possível, de construírem um saber acerca da significação social que querem ver reproduzida (marcando um direito à enunciação), de serem respeitados comunitariamente com relação a isso, aponta para a pertinência de democratização interna desses meios e denota o caráter de pertencimento e confluência no uso dos dispositivos lingüísticos. Descreve um técnico, remetendo-se à fala de um usuário sobre a referida crítica: “a mídia já falou demais de sofrimento... Eles querem que a gente fale disto... Eles não sabem o que é isto.” Quiçá o recurso da TV, o trabalho de construção e de produção de um saber próprio aos sujeitos envolvidos nessa prática, correlato à reinvenção de uma imagem social (marcada socialmente pela estigmatização, destituição e esquecimento face ao olhar do outro cultural), esteja permitindo a criação de um novo laço social na psicose e promovendo a recontextualização do lugar da loucura na sociedade contemporânea .

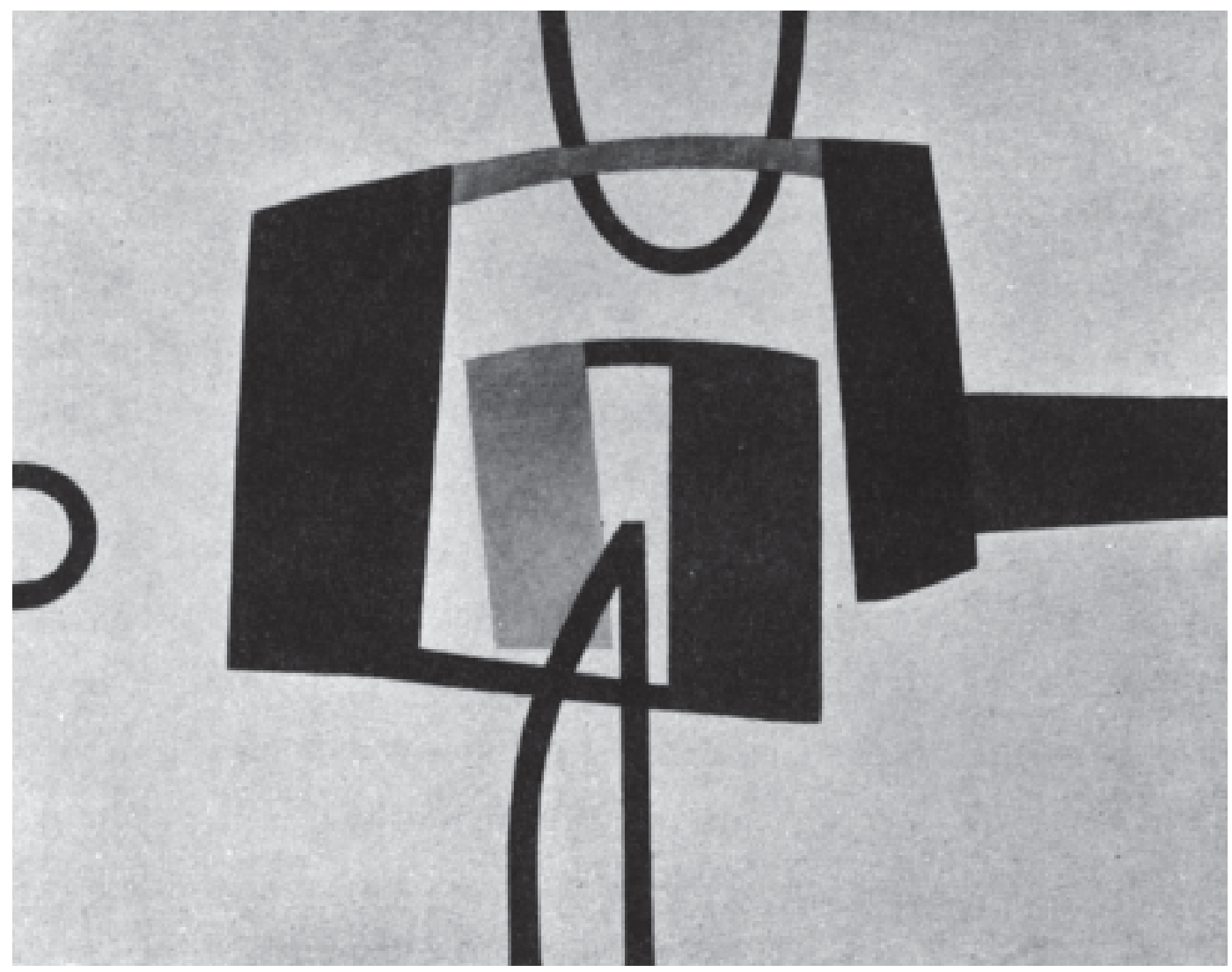


Comunicação e Saúde Mental:

a Democratização dos Meios Comunicacionais como Veículo de Reconstrução Identitária

Ilka de Araújo Soares

Rua Amarílio Lopes Salgado, 76/402 Cascatinha Cep.: 36033-290

Juiz de Fora/MG

E-mail: Ilkaars@terra.com.br

Recebido 02/04/04 Aprovado 25/08/04

BARBERO, Jesus, M. Dos Meios às Mediações - Comunicação, Cultura e Hegemonia. (Trad. Ronaldo Polito \& Sergio Alcides). Rio de Janeiro: UFRJ, 1997

Catálogo TV PINEL - Programas 1996 a 1999. Instituto Philippe Pinel , Ministério da Saúde, Rio de Janeiro, 1999.

CANCLINI, Nestor G. La Globalización Imaginada. Buenos Aires, Barcelona, México: Paidós, 1999.

FOUCAULT, Michel. Microfísica do Poder. Trad. Roberto Machado. Rio de Janeiro: Graal, 1986.

GUATTARI, Felix. Caosmose. Um Novo Paradigma Estético. Rio de Janeiro: Editora 34, 1992.

LACAN, Jacques. “ O Estádio do Espelho como Formador da Função do Eu”. In Escritos. Trad. Vera Ribeiro. Rio de Janeiro: Jorge Zahar, (1966)1998, pp. 96-105.

MARAFIOTI, Roberto. Los Significantes del Consumo - Semiologia, Medios Masivos y Publicidad . Buenos Aires: Biblos,1993.

MILLER, J.A. “Produzir o Sujeito?” A Clínica Psicanalítica das Psicoses. Atos da Escola da Causa Freudiana. Montpelier, 1983.

Referências

MUCCHIELli, Roger. Communication et Reseaux de Communications. Paris: Librairies Techniques Entreprise Moderne d’Édition, 1971.

PERUZZO, Cicilia M.K. A Comunicação nos Movimentos Populares - a Participação na Construção da Cidadania. Petrópolis: Vozes, 1998.

SODRÉ, Muniz. AMáquina de Narciso - Televisão, Indivíduo e Poder no Brasil. Rio de Janeiro: Achiamé, 1987.

SODRÉ, Muniz. Reinventando a Cultura - a Comunicação e seus Produtos. Petrópolis: Vozes, 1996.

THOMPSON, John B. AMídia e a Modernidade - uma Teoria Social da Mídia. (Trad. Wagner de O. Brandão). Petrópolis: Vozes, 1998. 